\title{
The Effect of Cigarette Smoking on Physical Fitness and Depression of Patients with Chronic Low Back Pain
}

\author{
Juhwan Lee, Sieun Park \\ Department of Physical Therapy, General Graduate School, Yongin University, Yongin, Korea
}

Purpose: This study was conducted to investigate the effect of cigarette smoking on physical fitness (dominant hand grip power, dominant isokinetic leg muscle strength, abdominal muscle endurance, flexibility, cardiopulmonary endurance) and depression in patients with chronic low back pain.

Methods: This study was a cross sectional study and subjects consisted of 60 young males with chronic low back pain. The subjects were allocated to two groups following a self-report survey: cigarette smoking group $(n=25)$ or non-smoking group $(n=35)$. Physical fitness (dominant hand grip power, dominant isokinetic leg muscle strength, abdominal muscle endurance, flexibility, cardiopulmonary endurance) were measured using objective methods and depression in patients with chronic low back pain was measured using the Korean version of center for epidemiologic studies depression (CES-D) scale.

Results: The results of this study were as follows: In physical fitness, the cigarette smoking group showed a significant decrease in abdominal muscle endurance, flexibility, and cardiopulmonary endurance compared with the non-smoking group. Depression index (CES-D scale score) was significantly higher in the cigarette smoking group than in the non-smoking group.

Conclusion: These results suggest that cigarette smoking had a negative effect on abdominal muscle endurance, flexibility, and cardiopulmonary endurance in patients with chronic low back pain. In addition, depression of patients with chronic low back pain was affected by cigarette smoking. Thus, we suggested that cigarette smoking may play a significant role in the deterioration of physical fitness and depression of chronic low back pain patients.

Keywords: Smoking, Chronic low back pain, Physical fitness, Depression

\section{서 론}

요통(low back pain)은 전세계적인 건강 문제로 보통 사람들의 $50-80 \%$ 가 일생중 한번쯤 요통을 경험하고 있다. ${ }^{1,2}$ 급성요통의 임상적 예후 는 좋은 편이어서 $95 \%$ 의 급성요통환자들은 발병 몇 개월 내에 회복 을 하지만, 회복하지 못한 요통환자의 경우 증상이 만성화된다. ${ }^{3,4}$ 만 성요통은 요통증상이 3 개월이상 지속되는 것으로, 급성요통환자의 흡연여부가 만성요통발현의 위험요인이 되고 있다.5,6 급성요통환자 가 흡연을 할 경우 만성요통으로 악화될 확률이 비흡연자보다 2 배 이 상 높았고, ${ }^{6}$ 흡연으로 인해 만성요통환자들의 신체기능점수 및 정신 건강점수도 낮아지게 된다.

흡연은 암, 호흡기계 질환 및 요통과 같은 근골격계 질환 및 우울증 상 발현에 기여하는 위험요인이다. ${ }^{8}$ 선행연구에 따르면 현재 흡연자 및 흡연 경험이 있는 그룹은 흡연을 한번도 경험하지 않은 그룹보다
높은 요통 유병률을 보였고, ${ }^{9}$ 하루흡연율(daily smoking)이 높아질수 록 우울정도도 증가했다. ${ }^{10}$ 또한 흡연을 함에 따라 체력요소인 심폐지 구력, 상지근력 및 자세유지근의 활성이 저하되기도 한다.11

한편 만성요통환자의 $50 \%$ 이상이 통증감소의 목적으로 흡연을 하 게 되지만, 통증감소의 효과보단 정신적 고통이 증가하게 된다. ${ }^{12}$ 만성 요통환자들 중 중증의 우울증상을 보이는 자는 본인의 일상생활능 력 수준을 저평가하고, ${ }^{13}$ 일상생활에 대한 문제해결을 회피하거나 일 상적인 활동에 수동적으로 임하는 경향이 있다. ${ }^{14}$ 때문에 만성요통과 같은 근골격계 통증환자의 증상완화를 위해 우울증상 감소를 위한 중재연구가 보고되기도 하였다. ${ }^{15,16}$

현재까지 흡연이 요통을 지속시키고, 정신과 증상 중 하나인 우울 증상 발현에 위험요인이 될 수 있다는 연구가 보고되어 왔지만, ${ }^{6,910}$ 만 성요통환자의 흡연유무에 대한 체력 및 우울에 대한 연구는 미흡한 실정이다. 
체력(physical fitness)은 측정 가능한 건강상태와 관련있는 심폐지 구력, 근력, 유연성, 신체구성요소(body composition), 신경운동상태 (neuromotor fitness)를 포함하는 것으로 정의된다.17 질환을 지닌 환자 에서 특이적으로 약화되어 있는 체력요소를 확인하는 것은 향후 환 자의 질환을 개선할 수 있는 중요한 요인이 되기 때문에 다양한 질환 을 지닌 환자를 대상으로 한 체력평가 연구들이 보고되어왔다.11,18,19 하지만 현재까지 흡연유무에 따른 만성요통환자의 체력에 대한 연구 는 미흡한 실정이다. 뿐만 아니라 만성요통환자들의 일상생활기능수 준을 저하시킬 수 있는 우울을 흡연여부에 따라 비교 분석한 연구도 미흡한 실정이다. ${ }^{14}$ 흡연유무에 따른 만성요통환자의 신체적기능 및 정신건강상태에 대해 보고된 현재까지의 연구에선 Short Form-36 Health Survey (SF-36), 흡연에 대한 질문지와 같은 자가기입식 설문지 를 통해 평가가 이루어졌고, 우울에 대한 평가는 이루어지지 않았 다.715 때문에 본 연구는 만성요통환자를 대상으로 흡연유무에 따른 체력(악력, 각근력, 복부근지구력, 유연성, 심폐지구력)에 대해 평가데 이터를 수치화 할 수 있는 객관적 측정장비를 사용하여 평가하고 흡 연유무에 따른 우울정도를 비교하여 흡연유무에 따른 만성요통환 자의 치료적 중재에 대한 기초자료를 제공하고자 한다.

\section{연구방법}

\section{1. 연구대상}

본 연구는 경기도 A병원 재활의학과 전문의에게 만성요통으로 진단 받은 20세 초반의 남성 중 실험의 목적과 방법에 대해 충분한 설명을 듣고 자발적으로 연구에 동의한 연구 대상자 선정기준에 부합하는 60 명을 대상으로 실시하였다. 연구대상자 선정 기준은 만성요통 외 다른 병력이 없는 자, Freitas 등 ${ }^{20}$ 의 흡연자에 대한 기준에 따른 비흡 연자와 흡연자에 해당하는 자로 하였다. Freitas 등 ${ }^{20}$ 의 기준에서는 현 재 흡연자와 같이 살고 있지 않고, 흡연을 경험하지 않았거나 흡연을 했더라도 경험기간이 6 개월 미만인자는 비흡연자, 최소 6 개월 전부 터 본 자료수집기간까지 계속해서 흡연을 할 경우 흡연자로 정하였 다. 하지만 현재 흡연자와 같이 살고 있거나 자료수집기간을 기준으 로 흡연자와 떨어져 지낸지 6개월이 지나지 않은자(간접흡연자), 자료 수집기간을 기준으로 이전 6개월 동안 금연을 해온자(이전흡연자)는 연구에서 제외되었다.

\section{2. 측정도구 및 측정방법}

1) 일반적 특성에 관한 설문지

본 연구에서 사용된 일반적 특성에 관한 설문지는 자가기입식 설문 지로서 8항목(나이, 키, 몸무게, 요통지속기간, 요통정도, 흡연유무, 흡 연기간, 하루흡연량)으로 구성하였다. 이 중 통증항목에 대한 평가는
Wang과 $\mathrm{Kim}^{21}$ 에 의해 수정된 주관적 통증평가표인 시각적 상사 척 도(Modified Visual Analogue pain rating Scale, MVAS)를 사용하였다. 통증정도는 0 (zero) 시점부터 환자가 표시한 위치까지의 길이를 $\mathrm{mm}$ 단위로 측정하였다.

\section{2) 체력 측정도구 \\ (1) 악력}

악력은 악력계(hand dynamometer)인 BS-HG (Biospace, Korea)로 측정 하였다. 연구대상자가 편안하게 선 자세에서 팔이 $15^{\circ}$ 의 각을 이루게 한 후, 중립 위의 자세에서 약 5 초 정도 최대의 힘으로 악력계를 우세 팔에 쥐도록 지시하였다. 3 회 측정값 중 가장 높은 값이 사용되었고, 악력은 $\mathrm{kg}$ 단위로 컴퓨터에 기록되었다.

\section{(2) 각근력}

각근력은 BS-LS (Biospace, Korea)로 측정하였다. 각근력 측정기구에 연구대상자는 허리를 곧게 편 자세로 앉아 양손으로 손잡이를 잡게 한 후, 우세측 다리에 최대한의 폄수축을 하도록 지시했다. 3 회 측정 값중 가장 높은 값이 사용되었고, 각근력은 $\mathrm{kg}$ 단위로 컴퓨터에 기록 되었다.

\section{(3) 복부근지구력}

복부근지구력은 BS-SU (Biospace, Korea)로 측정하였다. 복부근지구 력 측정기구에 대상자를 갈고리 자세로 눕게 한 후 대상자의 손을 귀 옆에 살짝 붙이도록 지시했다. 복부근지구력은 30 초간 기구 위에서 윗몸일으키기를 실시하게 하여 측정하였다. 복부근지구력은 횟수/30 초 단위로 컴퓨터에 기록되었다.

\section{(4) 유연성}

유연성은 BS-FF (Biospace, Korea)로 측정하였다. 대상자의 발바닥을 유연성 측정기구 플랫폼에 붙이게 하여 바른자세로 앉힌 후 양측상 지를 어깨높이에서 앞으로 뻗도록 하였다. 3 회 실시값 중 가장 높은 값이 사용되었고 유연성은 $\mathrm{cm}$ 단위로 컴퓨터에 기록되었다.

\section{(5) 심폐지구력}

심폐지구력은 BS-AB (Biospace, Korea)로 측정하였다. 대상자는 고정 형 싸이클에 앉은 후 페달링 시의 넙다리와 종아리가 이루는 각이 $10^{\circ}$ 가 되도록 바이크 안장의 높이를 맞춘다. 각을 맞춘 후 연구대상자 의 심박수 체크를 위해 고정형 사이클에 부착된 심박동 감지기를 잡 고 페달링을 시작한다. 측정은 6 분간 진행했으며 $\mathrm{mL} / \mathrm{kg} / \mathrm{min}$ 단위로 컴퓨터에 기록되었다. 


\section{3) 우울 측정도구}

(1) 통합적 한국판 Center for Epidemiologic Studies Depression (CES-D) 척도

통합적 한국판 CES-D 척도는 각 항목이 4점 척도로 구성되어 있고 측정된 점수가 높을수록 우울이 높음을 의미한다. ${ }^{22}$ 통합적 한국판 CES-D 척도의 점수 범위는 0-60점이며, 긍정적인 항목 $(4,8,12,16)$ 에 대 한 점수는 역으로 채점하여 총점을 계산한다. 한국어판 개발 당시 신 뢰도는 Cronbach's $\alpha=0.91$ 이었고, ${ }^{21}$ 본 연구에서의 신뢰도는 Cronbach's $\alpha=0.77$ 이었다.

\section{3. 연구방법}

본 연구는 단면연구로서, 경기도 A병원 재활의학과에 내원하거나 입 원중인 선정기준에 부합하는 대상자에게 연구의 목적을 설명하고 연구 참여에 대한 동의를 얻은 후 자가문답식 설문조사 및 체력에 대 한 측정을 실시하였다. 설문조사에는 일반적 특성에 관한 설문지 및 우울평가를 위한 통합적 한국판 CES-D가 포함되었고, 체력평가에는 우세측 악력, 우세측 각근력, 복부근지구력, 유연성, 심폐지구력 측정 이 포함되었다. 각 측정항목 간 휴식시간은 2분으로 설정하였다. 체력 측정은 평소 체력 검사를 진행해오던 물리치료사에 의해 실시되었고 연구대상자들은 자신의 측정값이 실시간으로 표시되는 모니터를 보 지 못하게 하였다.

\section{4. 자료분석}

본 연구에서 수집된 자료는 SPSS ver. 19.0 for Windows 통계 프로그램 을 이용하여 분석하였다. 모든 자료는 Kolmogorov-Smirnov 검정 방 법을 사용하여 정규 분포함을 확인하였다. 연구대상자들의 일반적

Table 1. General characteristics of subjects

\begin{tabular}{|c|c|c|c|c|}
\hline & $S G(n=25)$ & NSG $(n=35)$ & $\mathrm{t}$ & $\mathrm{p}$ \\
\hline Age (year) & $21.1 \pm 2$ & $20.9 \pm 1.2$ & 0.50 & 0.62 \\
\hline Height (cm) & $177.1 \pm 5.3$ & $174.9 \pm 5.7$ & 1.54 & 0.13 \\
\hline Weight (kg) & $75.7 \pm 14$ & $71.0 \pm 8.6$ & 1.49 & 0.15 \\
\hline $\begin{array}{l}\text { Duration of low back } \\
\text { pain (months) }\end{array}$ & $8.4 \pm 3.3$ & $7.4 \pm 2.4$ & 1.40 & 0.17 \\
\hline Low back Pain (mm) & $47.6 \pm 13.6$ & $46.7 \pm 16.8$ & 0.23 & 0.82 \\
\hline \multicolumn{5}{|c|}{ Duration of smoking (n) } \\
\hline$<6$ months & 1 & & & \\
\hline 6-11 months & 11 & & & \\
\hline $12-23$ months & 12 & & & \\
\hline$\geq 24$ months & 1 & & & \\
\hline \multicolumn{5}{|c|}{ Extent of daily smoking (n) } \\
\hline 5-9 unit & 2 & & & \\
\hline 10-19 unit & 14 & & & \\
\hline$\geq 20$ unit & 9 & & & \\
\hline
\end{tabular}

SG, Smoking group; NSG, Non-smoking group.
인 특성을 알아보기 위해 기술통계방법을 사용하였고 흡연군과 비 흡연군의 체력과 우울에 대한 차이를 알아보기 위해 독립표본 $\mathrm{t}$ 검정 (independent t-test)을 사용하였다. 또한 흡연유무가 체력 및 우울에 미치는 영향을 알아보기 위해 흡연유무에 따른 각 체력항목 (악력, 각근력, 복부근지구력, 유연성, 심폐지구력) 및 우울에 대한 단순선형 회귀분석을 실시하였다. 본 연구의 유의수준은 0.05 로 하였다.

\section{결 과}

\section{1. 연구대상자의 일반적 특성}

본 연구에 참여한 대상자는 60 명으로 이중 흡연군은 25 명, 비흡연군 은 35 명이었고 일반적 특성은 다음과 같다(Table 1). 흡연군의 평균연 령은 $21.1 \pm 2$ 세, 평균신장은 $177.1 \pm 5.3 \mathrm{~cm}$, 평균체중은 $75.7 \pm 14 \mathrm{~kg}$, 요 통지속기간은 $8.4 \pm 3.32$ 개월, 요통정도는 $47.64 \pm 13.57$ 점, 흡연기간은 6 개월 미만이 1 명, 6-11개월이 11 명, $12-23$ 개월이 12 명, 24 개월 이상이 1 명, 하루흡연량은 5-9개피가 2명, 10-19개비가 14명, 20개비 이상이 9명 이었다. 비흡연군의 평균연령은 $20.9 \pm 1.2$ 세, 평균신장은 $174.9 \pm 5.7$ $\mathrm{cm}$, 평균체중은 $71.1 \pm 8.6 \mathrm{~kg}$, 요통지속기간은 $7.4 \pm 2.4$ 개월, 요통정도 는 $46.7 \pm 16.9$ 점이었다. 두 집단 간 일반적 특성에 대한 유의한 차이는 없었다 $(\mathrm{p}>0.05)$.

\section{2. 흡연유무에 따른 그룹 간 체력 차이}

흡연유무에 따른 그룹 간 체력차이는 다음과 같다(Table 2). 체력항목 중 복부근지구력, 유연성, 심폐지구력에서 유의한 차이가 있었다 $(\mathrm{p}<0.05)$. 복부근지구력은 흡연군이 $17.16 \pm 6.56$ times/30 s, 비흡연군

Table 2. Physical fitness of patients with chronic low back pain following cigarette smoking

\begin{tabular}{|c|c|c|c|c|}
\hline & $S G(n=25)$ & NSG $(n=35)$ & $\mathrm{t}$ & $p$ \\
\hline Hand grip (kg.f) & $42.00 \pm 5.20$ & $44.36 \pm 6.12$ & -1.56 & 0.12 \\
\hline $\begin{array}{l}\text { Isokinetic muscle } \\
\text { strength (kg.f) }\end{array}$ & $43.76 \pm 9.40$ & $48.00 \pm 14.04$ & -1.31 & 0.19 \\
\hline $\begin{array}{l}\text { Abdominal muscle } \\
\text { endurance (Times/30s) }\end{array}$ & $17.76 \pm 6.56$ & $21.11 \pm 7.20$ & -2.1 & $0.03^{*}$ \\
\hline Flexibility $(\mathrm{cm})$ & $-1.62 \pm 12.21$ & $5.29 \pm 9.60$ & -2.35 & $0.02^{*}$ \\
\hline $\begin{array}{l}\text { Cardiopulmonary endurance } \\
(\mathrm{mL} / \mathrm{kg} / \mathrm{min})\end{array}$ & $42.81 \pm 11.57$ & $49.09 \pm 8.74$ & -2.39 & $0.02^{*}$ \\
\hline
\end{tabular}

SG, Smoking group; NSG, Non-smoking group

${ }^{*} p<0.05$.

Table 3. Depression of patients with chronic low back pain following cigarette smoking

\begin{tabular}{lcccc}
\hline & SG $(n=25)$ & NSG $(n=35)$ & $t$ & $p$ \\
\hline CES-D (score) & $22.60 \pm 7.90$ & $13.74 \pm 3.81$ & 5.19 & $0.00^{*}$ \\
\hline
\end{tabular}

SG, Smoking group; NSG, Non-smoking group; CES-D, Center for Epidemiologic Studies Depression.

${ }^{*} p<0.05$ 
Table 4. Simple lineal regression analysis for physical fitness and depression following cigarette smoking

\begin{tabular}{lcccccccccc}
\hline Variable/categories & $\mathrm{R}^{2}$ & $\mathrm{Adj} \mathrm{R}^{2}$ & $\mathrm{~F}$ & $\mathrm{p}$ & $\mathrm{B}$ & $\beta$ & $\mathrm{t}$ & $\mathrm{p}$ & $\mathrm{VIF}$ \\
\hline Hand grip (/smoker) & 0.00 & -0.02 & 0.01 & 0.94 & -0.13 & -0.01 & -0.81 & 0.94 & 1 \\
Isokinetic muscle strength (/smoker) & 0.01 & -0.01 & 0.67 & 0.42 & -2.68 & -0.11 & -0.82 & 0.42 & 1 \\
Abdominal muscle endurance (/smoker) & 0.75 & 0.59 & 4.72 & $0.03^{*}$ & -3.95 & -0.27 & -2.17 & $0.03^{*}$ & 1 \\
Flexibility (/smoker) & 0.09 & 0.08 & 6.01 & $0.02^{*}$ & -6.91 & -0.31 & -2.45 & $0.02^{*}$ & 1 \\
Cardiopulmonary endurance (/smoker) & 0.09 & 0.07 & 5.72 & $0.02^{*}$ & -6.28 & -0.30 & -2.39 & $0.02^{*}$ & 1 \\
Depression (/smoker) & 0.19 & 0.17 & 13.3 & $0.001^{*}$ & 5.64 & 0.43 & 3.65 & $0.001^{*}$ & 1 \\
\hline
\end{tabular}

${ }^{*} p<0.05$.

이 $21.11 \pm 7.2$ times/30 s로 비흡연군이 흡연군보다 유의하게 높았다 $(\mathrm{p}<0.05)$. 유연성은 흡연군이 $-1.62 \pm 12.21 \mathrm{~cm}$, 비흡연군이 $5.29 \pm 9.6 \mathrm{~cm}$ 로 비흡연군이 높았다 $(\mathrm{p}<0.05)$. 심폐지구력은 흡연군이 $42.81 \pm 11.57$ $\mathrm{mL} / \mathrm{kg} / \mathrm{min}$, 비흡연군이 $49.09 \pm 8.74 \mathrm{~mL} / \mathrm{kg} / \mathrm{min}$ 로 비흡연군에서 유의 하게 높았다( $\mathrm{p}<0.05)$. 비흡연군의 악력과 각근력이 흡연군보다 높았 으나 유의한 결과는 아니었다.

\section{3. 흡연유무에 따른 그룹 간 우울 차이}

흡연유무에 따른 그룹 간 우울차이는 다음과 같다(Table 3). 흡연군이 $22.60 \pm 7.9$ 점, 비흡연군이 $13.74 \pm 3.81$ 점으로 흡연군의 우울이 유의하 게 높았다 $(\mathrm{p}<0.05)$.

\section{4. 흡연유무에 따른 체력 및 우울에 대한 단순선형회귀분석 결과}

흡연유무에 따른 체력 및 우울에 대한 단순선형회귀분석 결과는 $\mathrm{Ta}-$ ble 4 와 같다. 분석결과 체력항목 중 악력, 각근력에 대한 흡연유무회 귀모형은 유의하지 않았으나 복부근지구력, 유연성, 심폐지구력 및 우울에 대한 흡연유무회귀모형은 유의했다( $\mathrm{p}<0.05)$. 체력항목 중 복 부근지구력에서는 흡연자에 비해 비흡연자에서 복부근지구력이 유 의하게 높았고 $(\mathrm{p}<0.05)$, 유연성에서는 흡연자에 비해 비흡연자에서 유연성이 유의하게 높았다( $<<0.05)$. 심폐지구력에서는 흡연자에 비 해 비흡연자에서 심폐지구력이 유의하게 높았다 $(\mathrm{p}<0.05)$. 우울정도 는 흡연자에 비해 비흡연자가 유의하게 낮았다 $(\mathrm{p}<0.05)$.

\section{고 찰}

요통 및 만성요통증상의 개선을 위한 현재까지의 연구에선 환자가 지닌 구조적 문제의 개선을 위해 실시된 PNF 기법, 멀리건 기법, 요부 안정근 강화운동이 요통환자의 요부근 활성화를 증진시킬 수 있고, 통증감소에 효과가 있다고 보고되었다.23-25 이러한 연구들은 요통증 상 개선에 있어 환자의 심리적, 환경적 요인보다는 구조적 문제에 초 점을 맞춘 연구이다. 하지만 만성요통환자는 구조적 문제 외의 직업 환경적 요인, 공포회피 반응과 같은 심리적 요인 저하의 특징을 지니
기 때문에 환자 치료에 있어 구조적 측면의 문제만이 아닌 환경, 심리 적 요인을 포함하는 접근이 이루어져야 한다. ${ }^{26}$ 이와 관련하여 흡연 하는 것이 요통을 지속시키고, 만성요통환자의 신체기능까지 저하시 킬 뿐만 아니라 우울증상을 발생시킬 수 있지만, 6.7 현재까지 요통환 자의 흡연에 대한 연구는 미흡한 실정이다. 때문에 본 연구는 흡연유 무에 따라 만성요통환자의 체력 및 우울 차이를 알아보고 향후 흡연 에 대한 치료적 중재의 기초자료를 제공하고자 실시하였다.

독립표본 t검정 및 단순선형회귀분석을 실시하여 만성요통환자 중 흡연군과 비흡연군 간의 체력 및 우울에 대한 차이를 알아본 본 연구결과는 그룹간 복부근지구력, 유연성, 심폐지구력, 우울에서 유 의한 차이가 있었다 $(\mathrm{p}<0.05)$. 흡연그룹의 복부근지구력 평균값은 17.16 times $/ 30 \mathrm{~s}$ 로 비흡연군보다 유의하게 낮았다 $(\mathrm{p}<0.05)$. 이는 흡연 유무에 따른 체력(복부근지구력, 유연성)을 평가한 Boyce 등 27 의 연구 와 유사한 결과로, 이 연구에선 흡연자의 복부근지구력이 비흡연자 보다 유의하게 낮았다 $(\mathrm{p}<0.05)$. 흡연자의 복부근지구력 평균값은 39 times/min이었고, 비흡연자는 47.2 times/min이었다.

흡연그룹의 유연성 평균값은 $-1.62 \mathrm{~cm}$ 로 비흡연그룹보다 낮았다 $(\mathrm{p}<0.05)$. 이는 Kanae 등 28 의 연구와 유사한 결과였다. 정상인을 대상 으로 실시한 흡연유무에 따른 유연성 차이를 비교한 결과, 흡연군의 유연성이 $2.2 \pm 10.2 \mathrm{~cm}$ 로 비흡연군 $(3.3 \pm 10 \mathrm{~cm})$ 보다 유의하게 낮았다. 하지만 본 연구결과와는 대조적으로 노인을 대상으로 실시한 Ricci 등 29 의 연구에선 흡연군의 유연성이 비흡연군보다 높았는데 $(\mathrm{p}<0.05)$, 이러한 결과는 흡연이 유연성에 끼치는 영향보단 대상그룹의 나이가 유연성에 더 큰 영향을 주었기 때문이라고 사료된다.29

본 연구 흡연그룹의 심폐지구력 평균값은 $42.81 \mathrm{~mL} / \mathrm{kg} / \mathrm{min}$ 로 비흡 연 그룹의 평균값보다 낮았다 $(\mathrm{p}<0.05)$. 이러한 결과는 군인을 대상으 로 1.5 mile에 대한 주파시간을 측정하여 심폐지구력을 비교한 Conway와 $\operatorname{Cronan}^{30}$ 의 연구와 유사한 결과였다. Conway와 $\operatorname{Cronan}^{30}$ 은 17 세부터 59세 군인을 대상으로 약 $2.5 \mathrm{~km}$ 구간에 대한 심폐지구력 평 가를 실시하였는데, 이 연구에서 $2.5 \mathrm{~km}$ 구간을 흡연군이 비흡연군보 다 늦게 주파했다 $(\mathrm{p}<0.0001)$. 흡연군의 주파시간은 $12.9 \mathrm{~min}$ 이었고, 비흡연군의 주파시간은 $12.3 \mathrm{~min}$ 으로 선행연구의 저자는 이러한 결 
과를 통해 흡연군의 심폐지구력이 비흡연군보다 낮다고 하였다.

본 연구에선 대상자들의 체력 외에 우울정도를 측정하였다. CES-

$\mathrm{D}$ 척도로 평가한 그룹 간 우울정도는 흡연그룹이 22.6점으로 비흡연 그룹 평균값인 13.74점보다 높았다 $(\mathrm{p}<0.05)$. 이는 Murphy 등1의 연구 와 유사한 결과로 선행연구에선 흡연그룹의 우울정도가 비흡연그룹 보다 3 배 이상 높았다 $(\mathrm{p}<0.05)$.

위와 같이 본 연구결과의 만성요통환자 흡연그룹의 체력 중 복부 근지구력, 유연성, 심폐지구력이 정상인을 대상으로 한 다른 선행연 구들에서 보고된 것과 같이 비흡연자보다 낮게 나타난 것을 확인할 수 있었다. 이는 흡연이 만성요통환자의 복부근지구력, 유연성, 심폐 지구력에 부정적 영향을 미친 것으로 사료된다. 복부근지구력의 약 화 및 햄스트링 근육의 단축은 요통발생의 위험요인일 뿐 아니라 요 통을 더욱 악화시킬 수 있다. $32-34$ 흡연으로 인한 심폐기능의 저하는 피로 저항력을 낮춰 피로를 빨리 느끼게 하고, 낮아진 피로저항력으 로 인해 보행패턴이 변화되어 근골격계 질환이 발생할 수 있다. ${ }^{35,36}$ 때 문에 만성요통환자 흡연그룹에 대한 복부근지구력, 유연성, 심폐지구 력 강화 및 흡연조절을 위한 중재법이 만성요통증상 개선을 위해 반 드시 필요할 것으로 사료된다. 또한 환자의 자세 및 물리적 환경이 환 자의 복부근지구력, 유연성, 호흡기능에 영향을 줄 수 있기 때문에 중 재와 더불어 적절한 자세교육 및 환자의 물리적 환경 조정을 위한 노 력이 함께 이루어져야 할 것으로 사료된다.3738

한편 만성요통환자 흡연그룹의 우울정도가 비흡연그룹보다 유의 하게 높았다( $\mathrm{p}<0.05)$. 우울과 같은 심리적 문제에 대한 접근이 이루 어지지 않을 경우 요통의 지속기간이 길어질 수 있기 때문에 흡연하 고 있는 만성요통환자의 우울정도에 대한 초기확인 및 관리가 반드 시 필요할 것으로 사료된다. ${ }^{39}$

본 연구는 만성요통을 지닌 20세 초반의 남성 중 특정병원에 내원 하는 자를 대상으로 하였기에 본 연구결과를 일반화할 수 없다는 제 한점을 가지고 있다. 또한 본 연구에서 평가한 체력항목에는 허리신 전근지구력, 등장성 복부근력 등의 항목이 포함되지 않았기에 향후 연구에선 보다 넓은 지역의 만성요통환자를 대상으로 보다 다양한 체력항목에 대한 연구가 필요할 것이다.

\section{REFERENCES}

1. Andersson GB. Epidemiological features of chronic low-back pain. The lancet. 1999;354(9178):581-5.

2. McBeth J, Jones K. Epidemiology of chronic musculoskeletal pain. Best Practice \& Research Clinical Rheumatology. 2007;21(3):403-25.

3. Carey TS, Garrett J, Jackman A et al. The outcomes and costs of care for acute low back pain among patients seen by primary care practitioners, chiropractors, and orthopedic surgeons. New England journal of medicine. 1995;333(14):913-7.
4. Koes BW, van Tulder M, Lin CWC et al. An updated overview of clinical guidelines for the management of non-specific low back pain in primary care. European Spine Journal. 2010;19(12):2075-94.

5. Cedraschi C, Robert J, Goerg D et al. Is chronic non-specific low back pain chronic? Definitions of problem and problems of a definition. British journal of general practice. 1999;49(442):358-62.

6. Holley AL, Law EF, Tham SW et al. Current smoking as a predictor of chronic musculoskeletal pain in young adult twins. The Journal of Pain. 2013;14(10):1131-9.

7. Derr MJ, Crisostomo RA, Hooten WM et al. Poster 237: Effects of Smoking on Treatment Outcomes for patients With Chronic Low Back Pain. Archives of Physical Medicine and Rehabilitation. 2008;89(11): e97.

8. Tønnesen P, Carrozzi L, Fagerstrom KO et al. Smoking cessation in patients with respiratory disease: A high priority, integral component of therapy. European Respiratory Journal. 2007;29(2):390-417.

9. Shiri R, Karppinen J, Leino-Arjas P et al. The association between smoking and low back pain: A meta-analysis. The American journal of medicine. 2010;123(1):87-e7.

10. Fergusson DM, Goodwin RD, Horwood LJ. Major depression and cigarette smoking: results of a 21-year longitudinal study. Psychological medicine. 2003;33(08):1357-67.

11. Macera CA, Aralis HJ, MacGregor AJ et al. Cigarette smoking, body mass index, and physical fitness changes among male navy personnel. Nicotine\&Tobacco Research. 2011;13(10):965-71.

12. Jamison RN, Stetson BA, Parris WC. The relationship between cigarette smoking and chronic low back pain. Addictive behaviors. 1991;16(3): 103-10.

13. Huijnen IP, Verbunt JA, Peters ML et al. Do depression and pain intensity interfere with physical activity in daily life in patients with Chronic Low Back Pain? Pain. 2010;150(1):161-6.

14. Weickgenant AL, Slater MA, Patterson TL et al. Coping activities in chronic low back pain: relationship with depression. Pain. 1993;53(1): 95-103.

15. Salerno SM, Browning R, Jackson JL. The effect of antidepressant treatment on chronic back pain: A meta-analysis. Archives of Internal Medicine. 2002;162(1):19-24.

16. Verdu B, Decosterd I, Buclin T et al. Antidepressants for the treatment of chronic pain. Drugs. 2008;68(18):2611-32.

17. Garber CE, Blissmer B, Deschenes MR et al. American College of Sports Medicine position stand. Quantity and quality of exercise for developing and maintaining cardiorespiratory, musculoskeletal, and neuromotor fitness inapparently healthy adults: Guidance for prescribing exercise. Medicine and Science in Sports and Exercise. 2011;43:1334-59.

18. Erikssen G, Liestøl K, Bjørnholt J et al. Changes in physical fitness and changes in mortality. The Lancet. 1998;352(9130):759-62.

19. Sörensen L, Smolander J, Louhevaar V et al. Physical activity, fitness and body composition of Finnish police officers: A 15-year follow-up study. Occupational Medicine. 2000;50(1):3-10.

20. Freitas ERSF, Ribeiro LRG, Oliveira LDD et al. Factors associated with the habit of smoking in elderly residents in Londrina city, Brazil. Revista Brasileira de Geriatria e Gerontologia. 2010;13(2):277-87.

21. Wang JM, Kim DJ. Assessment of spinal pain using visual analogue scale(VAS). Journal of Korean Society of Spine Surgery. 1995;2(2):177-84. 
22. Chon KK, Choi SC, Yang BC. Integrated adaptation of CES-D in Korea. Korean Journal of Health Psychology. 2001;6(1):59-76.

23. Kim SY, Kim NS. Effects of Mulligan's Mobilization with Sustained Natural Apophyseal Glides on the Paraspinal Muscle Activity of subjects with Chronic low back pain. J Kor Phys Ther. 2013;25(1):10-5.

24. Lee WJ, Park S, Park JW. Influence of Trunk Stabilization Exercise upon the Lumbar Stabilization and Foot Pressure in Patients with back pain. J Kor Phys Ther. 2014;26(1):21-6.

25. Kim K, Kim EK, Lee DK. Effects of PNF Patterns Exercise on Pain, Functional Disability and Fear Avoidance Belief in Chronic Low Back Pain Patients. J Kor Phys Ther. 2014;26(2):110-6.

26. Lee HJ, Song JM. Analysis of the characteristics of Patients with Chronic Low Back Pain Using the ICF Concept. J Kor Phys Ther. 2013;25(5):282-7.

27. Boyce RW, Perko MA, Joines GR et al. Physical fitness, absenteeism and workers' compensation in smoking and non-smoking police officers. Occupational Medicine. 2006;56(5):353-6.

28. Kanae O, Nobuyuki M, Noriko $S$ et al. The effect of cigarette smoking on flexibility in Japanese. Health. 2012.

29. Ricci NA, Francisco CO, Rebelatto MN. Influence of history of smoking on the physical capacity of older people. Archives of gerontology and geriatrics. 2011;52(1):79-83.

30. Conway TL, Cronan TA. Smoking, exercise, and physical fitness. Preventive medicine. 1992;21(6):723-34.

31. Murphy JM, Horton NJ, Monson RR et al. Cigarette smoking in relation to depression: Historical trends from the Stirling County Study. American Journal of Psychiatry. 2003;160(9):1663-9.

32. Taanila HP, Suni JH, Pihlajamäki HK et al. Predictors of low back pain in physically active conscripts with special emphasis on muscular fitness. The Spine journal. 2012;12(9):737-48.

33. Feldman DE, Shrier I, Rossignol M et al. Risk factors for the development of low back pain in adolescence. American Journal of Epidemiology. 2001;154(1):30-6.

34. Biering-Sørensen F. Physical measurements as risk indicators for lowback trouble over a one-year period. Spine. 1984;9(2):106-19.

35. Degens H, Gayan-Ramirez G, van Hees HW. Smoking-induced Skeletal Muscle Dysfunction. From Evidence to Mechanisms. American journal of repiratory and critical care medicine. 2015;191(6):620-5.

36. Benjaminse A, Habu A, Sell TC et al. Fatigue alters lower extremity kinematics during a single-leg stop-jump task. Knee surgery. Sports Traumatology, Arthroscopy. 2008;16(4):400-7.

37. Kim SY, Kim NS, Jung JH et al. Effect of Forward Head Posture on Respiratory Function in Young Adults. J Kor Phys Ther. 2013;25(5):311-315.

38. Park YN, Bae YS. Comparison of Muscle Performance of the Lumbar Region and Head Alignment According to the length of Sitting Time. J Kor Phys Ther. 2013;25(6):386-92.

39. Burton AK, Tillotson KM, Main CJ et al. Psychosocial predictors of outcome in acute and subchronic low back troble. Spine. 1995;20(6):722-8. 